\title{
FROM "GALAPAGOS SYNDROME" TO GLOBALIZATION: JAPANESE BUSINESSES BETWEEN TRADITION AND VIRTUAL REALITY
}

\author{
MARY REISEL \\ RIKKYO UNIVERSITY
}

\begin{abstract}
Fluctuating between accelerated globalization promoted by the government and the closed-island mentality termed the Galapagos Syndrome, Japanese businesses are at a historical moment of decision, having to choose between traditional work styles, old values, and stability on the one hand, and innovation, competition, and change on the other. Facing the growth of the high-tech world and the third wave of AI (artificial intelligence), businesses must confront these new rising industries, which are currently competing on the global arena, and change fast if they want to catch up and be part of the future global economy. The research presents the cultural factors that block traditional Japanese corporations from adapting faster to globalization, and follows the growing gap between traditional work style and the new virtual industries that are fast advancing.
\end{abstract}

Keywords: high-tech, globalization, language, Japan, harmony, uchi-soto, honne-tatemae.

"You know the day destroys the night, Night divides the day,

Tried to run, Tried to hide,

Break on through to the other side..."

-The Doors

"Well, in our country," said Alice, still panting a little, "you'd generally get to somewhere else - if you ran very fast for a long time, as we've been doing."

"A slow sort of country!" said the Queen. "Now, here, you see, it takes all the running you can do, to keep in the same place. If you want to get 
somewhere else, you must run at least twice as fast as that!"

"I'd rather not try, please!" said Alice. "I'm quite content to stay here..."

- Through the Looking-Glass and What Alice Found There

Lewis Carroll

\section{Introduction: Breaking through or Running in Circles?}

In the autumn of 2016, virtual anthropology, an emerging new research field in Japan, was raised on a pedestal in the shape of a lecture podium when I was invited to talk about the meaning of God in the development of artificial intelligence and the design of websites at a Tech conference in Tokyo. For several years I've been struggling to merge my academic studies in cultural anthropology with the virtual anthropology research I conduct for high-tech and Internet companies, and to create a new niche for applied anthropology in Japan. Then, finally, a breakthrough. My aims were, first, to explain the unconscious power the concept and the image of God have on people in monotheistic religions, believers and non-believers alike; and second, to show that every global Internet business and every single computer engineer has to be aware of the gap of emotional impact that images of God raise in different cultures and social groups. Ideas and images stimulate a high degree of feelings, emotions, desires, and imagination. They are the fuel behind any creative product and technology. From the imagery of Heaven and Hell created by the Dutch painter Hieronymus Bosch, through contemporary visions of the apocalypse brought about by robots in the popular movies of The Terminator saga and up to the cute Japanese robot Astro Boy, the lecture demonstrated the powerful and compelling influence that cultural values, historical images, and acceptable beliefs have in shaping and designing the unconscious collective imagination of users and their interaction with the virtual world. The audience at the conference was unusually challenging and new for me. It was composed mostly of computer engineers, mathematicians, web designers, scientists, developers, and one curious author who wanted to understand what an anthropologist was doing in a high-tech conference conducted in Japan, the land of Shinto where people live in peaceful harmony with millions of gods. It was indeed an unusual sight in Tokyo's tech world, a first blend of social sciences methodologies and computer science in a culture that is careful to keep fields of study and knowledge separated. But does it mean I actually succeeded in breaking 
through the glass ceiling of traditional Japanese business values and to introduce anthropology and new methodologies of work into the sphere of corporate practices? Or was it only this particular event, Rakuten's Tech Conference, which overtly aims to be a leader of change and the door to a new future in Japan? These are some of the main questions I am trying to answer in this study. To what extent have Japanese businesses started to open up to the idea of change? Are companies running ahead or going round in circles? Are they still sitting on the fence contemplating what to do, one foot in tradition and one in a virtual future, and like Humpty Dumpty cannot decide which side to take? Can't they take both sides and still move forward?

Anthropology in Japan is still perceived in the original meaning of the discipline, and the word itself, jinruigaku, means the study of humankind and its origins. It is therefore mostly focused on folklore studies and research into tribes located far away from civilization. The image of the anthropologist is that of an Indiana Jones, an adventurer dressed in shabby clothes, searching for secret and exotic tribes that are hidden in distant lands. Presenting yourself as a business anthropologist who is observing and researching corporate cultures, or as a virtual anthropologist constructing the cultural psychology of robots and artificial intelligence (AI) entities, raises not only an eyebrow but also a few smiles of misunderstanding. In Japanese society, every area and domain should have clear boundaries, and there is no mixing of different fields and specialities. This is a traditional cultural core-value of segregation between inside-outside circles represented in the concept of uchi-soto, according to which every group should be well defined and clearly separated from others at all levels of life, from personal to professional (Sugimoto 2010, Nakane 1970, Lebra 2004). Social life and business activities, from family to education, clubs and work teams, are conducted and organized in groups, and each person is expected to belong to specific groups, be fully identified with the groups and the members, and show meaningful commitment. Consequently, anthropology is part of academic research and university work, and business is business, therefore the two cannot meet. One can be an anthropologist or one can be a business person, and in some cases there is a third option of being an anthropologist conducting research in the world of business and presenting it to the academic community. But a mélange fusing and blending both fields is very difficult to create, since each side would consider such a blend crossing the lines of its own unity and becoming part of the other side. This is seen as a betrayal of group loyalty. The boundaries are clear: one can be either one of the team, or opposite the team, there are no in-between stages. "You are either with us or against 
us," a colleague explained the reasons for the lack of debates and open exchange of opinions in the meeting rooms. "There is no criticism and no grey zones in our business culture, it is either in or out. And nobody wants to be out." He was lamenting the lack of constructive criticism that could promote business, push ahead with new innovations and boost a healthy competition that will energize the decreasing economy and low consumption. "Each member in a group is afraid to say a single negative word, and there is no competition and no analysis or understanding of failures and mistakes." A recent study conducted by Kimura during the last year shows that the tendency to follow groups and opinion leaders is on the rise, and society is becoming more conservative and close rather than opening up. Kimura, a virtual anthropologist, focuses on netnography and analysis of online communities and social listening in the political arena. His latest research studies online comments regarding important issues such as conflicts with China and Korea. According to his study, only about one per cent of the people expresses an opinion and becomes leaders of groups, and others follow the leadership guided by emotional passions, the need to participate, and sometimes just a search to have some fun with the others. Whatever the reason, loyalty to the group is highly valued, and individualism, which was on the rise at the beginning of the millennium, is currently declining. Concepts like the inner group-uchishûdan - and strong authority— $k e n ' i$-are becoming central again, and liberalism is decreasing. People express a need for powerful authority and collective group values (Kimura, 2018).

Over time, I have met several anthropologists who were conducting interesting research projects outside the academic field, but their professional positions were at universities and their publications were academic in style and goal. Professional ethnographers who entered the business field could develop successful careers in marketing and market research, and are seen as part of the business world, but the work they do is quite limited. There is almost no concept of tailored market research and deep analysis of thick data unless the client is a foreign company that is familiar with the work-style and the meaning of ethnography in the corporate world and in ethnographic market research. Japanese marketers, like everybody else, try to follow each other, use similar methods, and have one definition of ethnographic market research.

My main professional aspiration for over a decade was to raise the value of anthropology in the business arena for the purpose of better communication and a more efficient workflow and for understanding cultural psychology and product design. But in spite of apparent curiosity and patience to listen to details and explanations, no one was willing to 
give it a real try. Many executives whom I met in different corporations understood very well the values that the discipline can add to their business, especially for Japan which has been in the process of globalization and expansion for a long time, but the typical answers I usually receive are: "Who has already done it by now?"; "Whom can we learn from?"; "Who can be our role model?" No matter what the added value may be, nor the urgent need or problem that has to be answered, there is always a demand to have a leader who has already been there, done that, and can be the first one to be followed. But if nobody wants to lead and create an open competitive field that might shake the balance of social harmony, how can there be a breakthrough? Clearly, then, the traditional image of the anthropologist is not the only barrier to change, and neither is the uchi-soto division. Japanese traditional culture preserves many values that shape the national identity, maintain a collective unity and bond the people together. Unfortunately, the same values that lead people and bring them together also hinder change, competition, and progress, and thus lead to stagnation, apathy, and regression. The things that shape a culture's uniqueness, charm, and strengths are also its weaknesses and shortcomings. This is true of nations, cultures, businesses and every single individual. Our strengths are also our weaknesses.

The study presented henceforth aspires to shed light on the strengths and weaknesses of the interdependency between Japanese business practices and historical-cultural values as seen through the distinct lens of applied anthropology. In its race to globalize fast, Japan is accelerating the gap that already exists between the new high-tech industries: the Internet and virtual services and traditional businesses such as trading companies, financial services and banks, which are the oxygen of every economy. While the former are running ahead and trying to cross the line of globalization in order to fast-forward Japan's economy, the later seem to be running horizontally and staying in one place. Whether, like Alice, they feel it is safer to linger in one place, or whether they still hesitate to break the fundamental codes of conduct that bind society and glue its identity together, the result is an accelerated divide between different fields of business and industries that will eventually lead to raptures in traditional bonds. At some point, each business will have to decide whether to follow the past or the future.

\section{The Invisible Bond: between Appearances and Reality}

Miyzawa Keiichi, Japan's prime minister from 1991-93, was fluent in English. Surprisingly though, Jørgensen mentions in his book that 
Miyazawa was harshly criticized in the Japanese media for his "display of perfect English" because there was a major concern that "he might disclose something in the foreign language that he ought to express differently and perhaps with more ambiguity in Japanese" (Jørgensen 2006:21). Jørgensen continues with an interesting anecdote reflecting the double set of values called honne-tatemae in Japanese culture: whenever Miyazawa was meeting foreign leaders in Japan, his own national territory, he was careful to speak Japanese and to communicate with the foreign delegates through an interpreter in spite of his own English fluency and the confidence he exhibited in foreign territories.

The duality of honne-tatemae is often used by Japanese to show the separation between the private and the public spheres of life. Honne means the real intentions and emotions of a person, the natural character and the true inner self, while tatemae is the proper façade expected in public spaces and within specific designated environments and it refers to the behaviour one should display towards the others according to social expectations and rules of manners. This dualism does not correspond to public manners and the notion of politeness in the Western sense, nor does it imply any moral or ethical meaning like the dichotomy good/bad suggests in Western codes of ethics. The Japanese duality of honnetatemae is directly connected to ideas of social harmony and to the demand to care about other people, to consider the other's emotions, and to save face in order to maintain a fruitful social interaction void of conflicts (Doi 1986, Lebra 1976, Nakane 1973, Naito 1992). It is also worth mentioning that Reishauer attributed the origin of honne-tatemae to the Chinese distinction of Yang and Ying, the light (a place that has sunshine) and the dark (a place where there is no sunshine), and the two sides are inseparably connected in a unique way which is characteristic and specific to Japanese culture and differs from the development of the idea in China and other Asian countries (Reishauer, 1977, quoted in Naito 1992). The concept of light/dark is rooted in different historical and philosophical origins and therefore conveys distinctive relationships in which the two sides combine and fuse into one. There is no light without darkness, and no darkness without light. This is strongly seen in manga and anime where characters do wonderful things, and then evil things, and all actions are presented as the normal behaviour pattern of the same character. There are no supermen and no superwomen in Japan, only normal people struggling to find happiness and live well. Honne and tatemae complement each other, and human nature is accepted much more openly for what it is, good and bad equally. 
However, as I mentioned earlier, our strengths are also our weaknesses. While the recognition of the round character of humans leads to higher tolerance, patience, and social harmony on the bright side, it also leads to a higher need of control of the darker side that has to be disguised in public spaces and social interactions. The fluctuation between social appearances and reality must be manipulated in a society that rejects all forms of violence and calls for harmony. Many researchers agree that the Japanese ability to maintain face and conceal their emotions is unique, as are their forms of communications and their complicated style of negotiations, nonverbal signs, and internal codes of conduct (Furuoka \& Kato 2008). During the years, I participated in many meetings that were conducted in a pleasant and welcoming atmosphere that seemed to be guaranteeing success and commitment to good future-business relationships. People are smiling, feel comfortable, and welcome the guests with complete attendance and focus. Yet, after the meetings are over, one of the employees suddenly would approach me quietly and mention indirectly, not to be too rough and insulting, that the boss was very unhappy, he did not like the potential client, and there was not going to be any other meeting. Sometimes the boss, or leader of the meeting, did not even raise his eyes to look around carefully at the whole team-one can never observe being observed and analyzed. Yet the other members felt the mood of the meeting and could tell without words what was to come. The members of the teams that consist the closed group and are working together, the uchi group, are famous for this unique ability to feel the atmosphere and the mood; to read the air is the typical Japanese expression, kuki-o-yomu. One must be able to sense everything without any verbal sound, visible look, or detectable body language. And now try to imagine how a meeting looks when traditional Japanese businessmen face a group of successful and confident Americans, full of energy and trying to impress with a long presentation constituting half-an-hour of endless and fast speech. Actually, the most recurrent question I often received from colleagues is: "Mary-san, how can you make Americans be quiet?!!! Just for a short time? One quiet minute! I always end up with such a headache. It is unbelievable how much energy they have to speak so endlessly." And usually, the Japanese end up not only with a headache, but also without being able to say a single word, since they are taught not to break in, but to let the other finish before they speak. While harmony leads to good sensing of the air and proper behaviour in Japan, it leads to stagnation and paralysis in the international environment, and thus to many lost opportunities of business deals, promotions, and negotiations. This is a step that is still difficult to reach: the ability to be assertive enough to stop a conversation in the middle and 
present your own business interests and goals. Passivity is still the dominant pattern in many places.

However, harmony at home leads to loss not only in the international race for globalization but also inside the homeland. Research into one of the most important fields of life - health care and medical servicesshows that the need to sustain harmony in the workplace and work relationships is causing nurses to perform below expectations, and to mistakes in decision-making owing to the conformity and the pressure of harmony relations (Konishi et al, 2009). Deep ethnographic research and interviews with nurses showed that clinical nurses are too worried about relationships with physicians and senior nurses, and as a result they follow orders without debate even when they disagree or think the orders may hurt the patient. The study brings worrying results and the testimony of nurses in constant conflict and inner dilemmas: "The infusion should be reduced, I thought, but if I resisted the doctor, I was sure that he would become furious, and this would affect my nurse colleagues. So I could do nothing but follow the doctor's orders" (quote in Konishi et al, 2009:629). But in spite of the internal conflicts, the study concludes that nurses value very highly the traditional $w a$ and maintain politeness and respect even when they lead to questions regarding ethical behaviour and problems in decision-making.

The inability to face authority and to make good decisions, or any decision at all, has recently been severely criticized in the media due to the growing number of big corporations that are facing serious problems, many of which caused by employees' refusals to criticize the boss and to express their own opinions even when they know a major mistake might take place and damage the whole company. Nissan faced the major problem of a shortage of highly qualified personnel, which was not reported in time even though everybody knew about the issue. Toshiba faces bankruptcy because of bad investments the company made in the nuclear sector in the USA following the collapse of Westinghouse, which had already filed for bankruptcy a few months earlier (April 2017). Critical research recently published in the Asahi revealed that employees knew the investments were a very bad decision that would bring the company down, but they felt they could not say anything even to their own colleagues, let alone their superiors or executives. The writer, Owada, warns companies not to repeat the mistakes of Yamaichi Securities from the nineties, and not to incur bankruptcy because people cover up for each other due to their loyalty to workplace harmony and its control over decision-making (Asahi, 2017/11/24). 


\section{The KY Generation: from air of harmony to air of discord}

Harmony tends to block conflicts and produces a good atmosphere: it is therefore important to mention that the purpose is always a positive one. The most famous battle in Japanese history, the battle of Sekigahara, which unified Japan after a long period of wars and political rivalry, is a symbol of the spirit of Japan. The age of unification and the perception of Edo period as the beginning of harmony and peace are a reminder to everybody what war and lack of harmony can lead to, and that peace is the only way to live together. Even the debate on constitutional change is being conducted under the need to maintain peace and harmony. While some Western researchers and people criticize harmony and claim it is hypocritical, the Japanese avoid expressing opinions and contradicting others for the exact opposite reason, that they don't want to hurt other people by saying the wrong thing, even accidentally.

"This is why Japanese take so much time to order in the restaurant, especially when it is a business meeting," Yuka, one of my young business colleagues was trying to explain over lunch the secrets of kuki o yomu, reading the air properly. "I am always worried I might order something somebody else really doesn't like and I will ruin the lunch for everybody. So when I order, I should do my best to feel the emotions of the others and try to hint about some foods I would like to eat in order to see what they think about it, and after I feel reassured that everybody likes my choice, I can order. You need to know how to read people very well here. If someone says the dish is bad, it is a direct criticism of my choice. I made someone feel bad. This is very wrong to do." Reading the air is easier in business because it is always the one higher in position that has to choose the food and the others only follow, quite a relief if you are so worried about not hurting other people's emotions just because of the wrong omelette. Some readers might remember the famous scene from the movie Tampopo, in which a young employee chose a different dish from the rest of his older business colleagues and everybody stared at him with a shocked expression for not following the boss's choice of food as expected (Tampopo, 1985, director: Juzo Itami). On the other hand, there is great sensitivity and awareness to the needs of others, and business people know very well that they should not offer alcohol to anyone whose religion is unknown in order not to hurt their feelings unintentionally. The global Internet company, Rakuten, even designed special prayer rooms for Muslims in order to accommodate employees coming from Muslim countries, a good and comfortable environment for their religious practices. The company's cafeteria also provides a variety of food and 
special vegetarian dishes for Indians who prefer to have Indian food. The need for harmony accommodates many people in different ways and proves highly valuable in an international multicultural corporation.

The concept of $w a$ appears in everyday life in many places and aspects, from the need to harmonize food and to unify (and limit) the taste of groups up to $w a$ cloths, $w a$ interior design, $w a$ body language, $w a$ smiles, and much more. The roots of harmony are embedded in far-distant history and are core values in both Shinto and Confucianism; it is therefore no longer a value, but a way of life, and a state of mind that hovers over all cultural and daily activities (Konishi et al, 2009). I have met several senior executives in important positions who openly said that they would have no hesitation in giving up a good business deal if they thought it might endanger the harmony of the group and lead to unrest or the dissatisfaction of many. In a panel conducted in the New Economy Summit in Tokyo (April 2017, The New Otani Hotel), a group of foreign executives and Japanese were discussing changing values of work, and the issue of harmony above all was mentioned out loud as an unquestionable uniting way of thinking for all, even above competition.

"This is really bad, the young generation doesn't want to go to nomikai any more, I can't believe it, Mary-san! I asked one of my young employees to join our drinking party last night, and he said openly he has to go home to his wife. I am so shocked!" It has been almost a decade since the president of an international chemical company in Japan openly complained about the young generation showing disobedience and signs of rebellion by not following traditional values that were unquestionable for his generation, the corporate salary-men who built the economic miracle in the bubble age and were termed samurai in suits. They never said no to their superiors, showed respect and loyalty to the company and country above all, and were willing to serve whenever necessary. But in recent years, more and more executives complain about the lack of unity and changes of behaviour. Young employees refuse to go to drinking parties, do not participate in different group activities, and even change jobs of their own free will, rather than showing full loyalty to the one company they work for. Older businessmen and managers express their worries about the future of Japan if young people break traditional values and stop respecting harmony and group collaboration. But it doesn't help. Interviews I conducted in the last two years with students between ages 18-22 (28 men, 16 women, interviews conducted in 2016-7) show a change seen in contradictory results. On the one hand, they follow the pattern I have seen in Kimura's study mentioned above, a need to follow authority, and a search for role models with a strong personality to guide 
them; and on the other hand, a desire for more freedom and individual choices in every aspect of life, from choosing temporary jobs to refusal to marry. They do not like to think of others too much, and they show a lack of sensitivity to the atmosphere and the needs of others.

The KY generation. KY, kuki yomenai, is a new term that popped up in the media several years ago, and it means "cannot read the air" i.e. a generation that no longer has the sensitivity and awareness of the importance to feel the air without verbal communication and open explanations. KY applies to a generation that will have difficulty blending well in to a traditional business environment since they pose a major threat to harmony and smooth relationships in the workplace. In spite of the fact that patterns of change already started appearing at the beginning of the millennium, the Japanese media, as in other cultures, points the finger firmly at the mobile phone and the new high-tech wave as the main causes of the KY generation's collapsing harmony, the inability to show social tact, and the lack of proper sensitivity to others (Underwood \& Okubayashi, 2013). However, the lack of traditional social sensitivity is exactly what makes the younger generation adjust well and fast to the new workplace and the new environment of the Internet and high-tech, where quick decisions and innovations are necessary. While I see that big businesses still suffer from major obstacles in the shape of harmony and an inability to make decisions, I also see new forms of work-style, more openness, and much more fluent communication among the younger employees. The problems at the executive level - sticking to conformity in spite of the high cost to corporations - are still big. As Alston \& Taki observed in their study over a decade ago, when it comes to the meeting rooms in corporate culture, the values of tatemae and wa still rule and flatten communication to a horizontal line resulting in a slow process of decision-making and formal behaviour lacking an expression of real opinions (Alston \& Takei, 2005). Corporate culture is at the beginning of a wave of change, starting from the bottom up, a typical movement in Japan. Many changes started from the bottom up and eventually changed society, the most conspicuous and meaningful being the otaku and their impact on the concept of masculinity and work. As I will show, these concepts are slowly crawling into corporate culture as well, aided by the declining economy, the adoption of English as a business tool and ideology in the high-tech and Internet worlds, and the development of the new Internet business which is already setting new values and new forms of work suitable for the young KY generation. 


\section{From Language of Segregation to Language of Integration: English as Harmony and as Discord}

The Japanese people have complicated relationship with the English language and their attitude has been fluctuating up and down from the initial introduction of the language in Meiji period up to the present day. During WWII the language was associated with the enemy, but the attitude changed during the occupation, and the status of English quickly improved. English education was introduced through a variety of forms and places, from language clubs, fashion magazines and Hollywood movies, to ballroom dancing and classical music. Soon, English became associated with many social practices borrowed from foreign ideologies that were exotic and strange to the Japanese culture, such as kissing, hugging, and dating (McLelland, 2012). Yet English has always remained the language of the Other. The language of another race, of movie stars, of foreign people with strong and visible body language, loud voices, and open sexuality. People who had no tatemae, who came into the islands as conquerors, and were not forced to follow the rules of harmony. English was the language of the people who defeated the Emperor after 2000 years of stability and collective harmony. Many Japanese studied English as it was the spirit of the age and part of their education, but it didn't become a spoken language even after it entered the curriculum, and most people in Japan still do not speak it even nowadays.

The status of English changed slightly in the eighties, at the height of the bubble age, when Japan was at the peak of its globalization and national confidence, but the short anecdote about PM Miyazawa mentioned above clearly demonstrates the lack of acceptance and the real internal ambiguity within the uchi groups inside Japan. The growth of political power balanced the usage of foreign language and foreign personnel with the development and expansion of theories of the uniqueness of the Japanese people, Nihonjinron. These theories controlled the eighties and the age of the bubble economy, and provided an open backlash to the era of occupation and the control of the Japanese identity by the Other. The discourse of nihonjinron was characterized by an increased search for the unique identity of the Japanese people and their superiority to the symbolic West (Befu 1993, 2001, Jorgensen 2006, Lebra 2004, Sugimoto 1999, Smith 1995). Within the discourse of Nihonjinron, the Japanese language was the central axis of power, social control and the defining feature of Japanese identity. Nihonjinron presented a Foucauldian discourse analysis based on the same philosophy, that language creates and moulds the unique character of the people, and serves the same purpose of creating 
a homogenous form of thinking and behaving based on an ideally common view of history that the people share (Foucault, 1969). It is therefore inevitable to assume that policies regarding language education and the attitude to the penetration of a foreign language into the culture were seen as intrusive and dangerous, even in periods of internationalization and globalization. Like any other policy, language policies, are bound to reflect ideologies and processes of power and control (Liddicoat, 2007). According to Liddicoat, the discourse of Nihonjinron blends language and race together and presents them as one, a unity that results in language actually becoming part of race, and not a facet of national identity or social belonging. Nationality in turn becomes part of race and language, and therefore the Japanese language has been seen as distinctive and singular in the world and it accurately reflects the uniqueness of the Japanese people as a race and as a nation (Miller, 1982). Within this frame, English was established as the language of internationalization and a tool of communication in the global arena, and it was cut out of the connection to education, as well as to other languages that could be studied for curiosity, knowledge, or other purposes. In Japanese terms, English became the language of the soto, and was expelled not only outside of the Japanese uchi but outside of the circle of other languages as well.

The teaching of English in the eighties was then connected to the process of the internationalization of Japan and the economic boom, since the goal of globalization was North America as a focus, and the European countries where most people could communicate in English. Liddicoat shows that the purpose of teaching English was centred on the promotion of Japanese culture and values that should be fostered in the world beyond Japan. It was therefore not necessary for most Japanese people to study English, a policy that the Ministry of Education did not alter, even in the new millennium (Liddicoat, 2007:37). It explains why many Japanese even nowadays still do not understand why they need to study English. The direction of English was from the inside to outside, and not the other way round. The study of English became strongly connected with the meaning of being Japanese, and the foreign language served as a tool for assisting internationalization and helping Japanese understand themselves better, language was an outcome of the need to explain Japan to the Other located outside of Japan. The benefits of language education were twofolded and this assisted the construction of the Japanese image and the definition of a clear national identity and character. English was the mirror image through which the new Japan could redefine itself after the Fall.

By 1989, language education was presented openly as a dichotomy between Japan and the West. Edwards shows in his research that the 
conflicts embedded in the English-language problem created complicated ambivalent emotions and anxiety among the Japanese, who on their side felt they were "being judged inferior internationally on the one hand, while supporting feelings of cultural, and ultimately racial, superiority on the other" (Edwards, 1989:157). In his concluding comments, Edwards emphasized the ambiguous relationships Japan portrayed in its attitude to the West, which essentially displayed the constant confusion that the Japanese had about themselves and their own identity in a period of turbulent changes and fast globalization. This sense of confusion only increased in the nineties with the collapse of the bubble economy on which many of the above values were based, and in which the identity of the people, their unity and their pride were rooted.

Surprisingly though, the attitude towards English as the language of business and internationalization has not changed even today. Most people have basic level of English since everybody studies English at school, but most people I talk to still feel they have no need to speak and understand English well. The language has not become associated with knowledge, intellectual gains, self development, or even tourism and pleasure. Japanese travel overseas mostly in groups, and in central Tokyo, where I live, very few shopkeepers speak English in spite of the boom that the foreign tourism industry has been experiencing since 2015. English is being positioned as a key to globalization and not as a need to learn about the world. The need for globalization is itself seen as a temporary necessity due to the decreasing economy but many still hope it is indeed a temporary problem and that Japan will either prevail or learn to live with a lower-scale economy. It is therefore left only for the major international corporations who keep expanding outside Japan to wave the flag of English as a tool for the future of Japan. However, as high-tech and robotics become the new Cool Japan and a potential door to a better future, English becomes more popular and more Cool itself. The 2020 Olympics (to be held in Tokyo) are also creating a boost for many new industries, all of them rising from the new apps world and advanced virtual services, since eventually all the information will be online. It will be interesting to see in which fields of life English will become central and in which fields it will be absent. There are many $u c h i$ spaces where English will never be allowed to enter.

\section{In search of a new sources for harmony}

Change, hen, was the kanji (Japanese character) chosen to be the kanji of the year in 2008. This was one of the most dramatic years in the new 
millennium so far, a year following surprising changes in the government with the resignation of Shinzo Abe in September 2007, and the global financial meltdown that had a severe impact on the financial world and the banks. For over three decades, the Japanese Kanji Proficiency Society has chosen the kanji of the year, with the target of pinpointing one buzzword that can neatly represent the major events and the zeitgeist, the spirit and the mood of the specific year. "Change" was chosen in order to raise the spirits of the people above the cloud of the collapsing economy and the financial crisis, and to create the feeling that a positive turn was just around the corner. Interestingly though, "Change" did not pass into history after the year ended, and the symbolic power of the word remained and was even strengthened when it was added to companies, the media, and many different promotional campaigns. The return of Shinzo Abe in 2012 and the implementation of Abenomics, accompanied by new globalization and a big boost to Englishization in business, provided a new springboard for ideas about change and innovation. Shinzo Abe, facing a long deflation, low citizen confidence, lost pensions, fluctuations of the yen, and many internal social problems, started with changes to the monetary system and the BOJ (Bank of Japan), and pushed reform in language and English studies all over the country. The curriculum changed, and in several companies English was established as the main language. But then again, traditional values created serious barriers to speeding ahead and away from the vicious cycle of running in the same place. The attempt to use Change as a harmonizing word was successful, but the idea of Change itself is limited and was shaped to match tradition rather than the future. The KY generation can look for new jobs, but within the limits of existing values.

\section{The Education Barrier: Facing the Recruitment Trap}

"I'm wasting all my academic year on job interviews and meaningless recruitment, and nobody hires me. They think my education and different way of thinking will create problems for everybody else. People like me break the harmony of society, nobody wants it here." Takeshi was one of my research assistants, a bright young man who returned to Japan after a year in a prestigious American University where he studied politics and international law. One would think that everybody would jump at the possibility of having such knowledge, and at a young person with bilingual ability, and yet, when I met him during the job-search process, he was depressed and disappointed. He was walking with a few other friends to a job seminar intended for students, seminars that are conducted during 
the semester even though the government has demanded that companies stop the traditional habit of running job seminars during the academic year. But it was in vain. Seminars are run during the third and fourth years, and students in Japan study much less than their fellows in most of the developed world, as well as in several Asian countries by now. "I wish I could study more, it's the last year and I also haven't found a job yet," complained one of the young female students in the group. "This is such a waste of time." The students were all dressed in traditional black dull suits, and shared the same gloomy feelings of hopelessness.

The recruitment styles in Japan are highly conservative and have so far managed to resist major changes. The literature on recruitment is extensive, and shows it is one of the highest walls yet to be climbed (Jacoby, 2005; Firkola, 2011). Traditional recruitment practices were designed in the seventies and eighties, and sought to establish connections between future employees, who were still students, and potential future companies. Students used to start their job-hunting in the third year (and sometimes even at the end of the second year) of their studies. By the end of university, students would already know which company they would go to and to what field of industry they belonged. According to Firkola's study, there are changes in the system owing to the changing economy, and he observes a rise in recruitment and higher competition between 2006-2008, followed by a decrease after the global financial meltdown. While there are naturally changes due to changing needs and to the disappearance of life-long employment even in big corporations, the university recruitment style hasn't changed, and students have to follow the same pattern of losing a lot of studies because of the obligation to attend many job seminars. Hence the university gains different meaning in each year. In the first year, students are expected to join clubs and perform in social groups, and these activities end up as part of their performance to be added to their CVs and professional profiles for recruiters. The second year is the most meaningful in terms of studies, and many feel this is the year they actually study and gain knowledge and academic experience. But from the third year, they join the job hunt and with the fear of further economic decline in the future, they usually keep searching for jobs even if they have already found a job they like. As they explained in an interview, the first job is a guarantee that they have a job after university so they can then start searching more comfortably for something they would really like to be doing.

Due to the lack of space, I do not wish to go into the effect such new patterns of search have on companies and recruiters. Suffice to say that these fluctuations, and sometimes last minute changes of workplace, are 
changing the market and making it more vital and competitive. They enable students to have a free choice and to think for themselves about their future career, according to their own skills and preferences. However, the freedom and the choice remain only within the Japanese work force. The loss of academic knowledge and the lack of basic skills end up creating a market of young people who are talented, motivated, pushed by the economic situation but unfit for international competition in most labour forces. Their ability to develop is also limited by their lack of studying skills or any capacity for deep and strategic critical thinking. Their best contribution is their honest desire to work, contribute and be part of the team.

Returning to Foucault (1969), discourse and language have the power to shape reality and change society, and the Japanese political and social establishments are aware of the danger of critical thinking, which is the source of the development of ideas of the uniqueness of Japanese people and the need to stay far from the outside world. Rear shows in his analysis that the issue of critical thinking is being debated again and again in the creation of public policies, and it is controlled to match political as well as business interests (Rear, 2012). Rear's conclusions, though, show a change. While it was easy to control the education and obedience of citizens in the decades after the war since the nation faced common goals and obstacles, it is becoming more challenging as time passes and ideas of individuality and independence enter the country along with the need for creativity and innovation. Japan is facing a different stage of its development with a negative birth-rate and an open Internet system. I can only add that the transition from Japan's most popular SMS a decade ago, Mixi, to the global Facebook, very often used in English, marks a significant change no less important than the fluctuating economy and labour market, especially since it was led by the Fukushima disaster, a rupture of trust that is far from healed.

\section{Discussion: Words, Images, and the Consumption of Emotions}

The Rakuten Technology Conference is an annual tech event that has been organized for several years now by the Rakuten Institute of Technology (R.I.T.), and supervised by Mori Masaya, the founder and manager of R.I.T. and of Life Tech Lab. A few years ago, when I met Mori-san for the first time, he expressed his strong wish to raise education and globalize his research institute members as much as possible. "English is not just a language, it is knowledge, it is a way of thinking, it is really 
becoming a global mind in the true sense of the word. I have to bring this way of thinking to my members and to Japan. We have to change and advance to the world." Mori-san himself is setting an example by constantly learning new things and taking actual steps to change and to motivate all of his members to have state-of-the-art knowledge and new methodologies for professional development. He was the first executive to open the door to anthropology in the corporation by inviting me to present and explain the value of anthropology in the cyber world to a team of computer engineers and product developers. R.I.T. management also encourages foreign employees to study and promote their education, an opportunity that most companies in Japan do not offer to their foreign personnel. The training provided to foreign employees is focused on the acquisition of Japanese and job-centred proficiency, according to the needs of the company they work for. Training is usually done in traditional ways, with the purpose of teaching people the specific set of skills they need in order to properly perform their jobs. However, members of R.I.T. are encouraged to join challenging professional events such as presentation in global Internet and high-tech conferences, participation in workshops in MIT, taking advanced English lessons, and even private training with an anthropologist. R.I.T. is trying to follow Star Trek and to go where no one has gone before, to reach the place where English is no longer a language but a source of new knowledge, innovation, competitive values and independent critical thinking. It may be taken for granted that the World Wide Web reaches everybody, and the industry must find ways to overcome local and global obstacles on the way, from language to financial exchange and to international laws, but as this research has shown, there is still cultural conservatism and a fear of the erosion of traditional culture, a process that indeed happens in Japan and in other countries as they start opening up. There is a need for a major change in the mindset and attitude of traditional business in order to face change with a challenge instead of fear. Can that be done? Can the spirit of change, challenge, and globalization spread? While high-tech is waving the flag, the others do not seem to follow fast enough. The high-tech world seems to have created its own uchi environment, from which others are excluded. If this is indeed the process that is currently taking place, change will arrive at pockets of industries in very small doses. But I do not think this is the reality.

In a thought-provoking article about the influence of otaku culture on mainstream culture and gender perception in Japan, Condry (2011) follows the journey of the otaku image from the oblivious dark-side of society in the eighties onto centre-stage in the form of Cool Japan and the rising 
consumption of the virtual. The flow of anime and manga characters through different forms of media, virtual and real, and the emotions involved in the process, have created a massive economic power that globalized the whole world with products of Japanese anime and ended up being the second economic miracle following the bubble. Condry, a cultural anthropologist, continues to show that the otaku influence did not stop with the new economy and the rise of affective labour in Japan, but continued with the design and filtering of new images and ideas of masculinity and new spaces for alternative manhood in a world far removed from the traditional salaryman. Murakami Takashi, Japan's bestselling pop artist, presents the same ideology while explaining that his art is not a copy of American art, but derives from otaku, and from traditional Edo imagery. It is rooted in old Japanese aesthetics, imagery and ideology. I believe that any change that is initiated in Japanese society starts only from the inside, from the needs of the people and their mutual understanding and harmonious collaboration. While there are different opinions about globalization in Japan accompanied by strong resistance to change, and there is political debate about the nature of change, everybody knows that the future is not bright, and that there has to be better collaboration for a better future. The Galapâgos turtles may move slowly, but they move safely and they reach their goal.

\section{References}

Alston \& Takie. (2005). Japanese Business: Culture and Practices. NE:iUniverse.

Befu, H. (1993). Nationalism and Nihonjinron. In Befu H. (ed.) Cultural Nationalism in East Asia: Representation and Identity. University of California.

—. (2001). Hegemony of Homogeneity: An Anthropological Analysis of Nihonjinron. Melbourne: Trans Pacific Press.

Carlie, L. E. (1998). Business and government relations in Canada and Japan: the 'homestead' and the 'public vessel'. In Nagatani, K. \& Edgington, D. E. (eds.) Japan and the West: The Perception Gap. UK: Ashgate.

Condry, I. (2011). Love Revolution: Anime, Masculinity, and the Future. In Fruhstuck, S. \& Walthall A. (eds.) Recreating Japanese Men. University of California Press.

Doi, T. (1986). The Anatomy of Self. Harbinson, M. H. (trans.). Tokyo: Kodansha International. 
Edwards, W. (1989). Internationalization, Nihonjinron, and the Question of Japanese Identity. In JALT Journal, 11:2, 157-166.

Firkola, P. (2011). Japanese Recruitment Practices - Before and After the Global Financial Crisis. In Economic Journal of Hokkaido University, 40, 59-71.

Foucault, M. (1969). L'archéologie du savoir. Paris: Éditions Gallimard.

Furuoka, F. \& Kato, I. (2008). The 'Honne-Tatemae' Dimension in Japan's Foreign Aid Policy. In Electronic Journal of Contemporary Japanese Studies.

http://www.japanesestudies.org.uk/articles/2008/FuruokaKato.html [Accessed: November 2, 2017]

Jacoby, S. M. (2005). The Embedded Corporation: Corporate Governance and Employment Relations in Japan and the United States. Princeton University Press.

Jørgensen, N. J. (2006). Culture and Power in Germany and Japan: The Spirit of Renewal. UK: Global Orient.

Kimura, T. (2018). The Reasons Liberalism is Disparaged in Online Public Opinion (Neto yoron de hoshu ni tatakareru riyu - jisshoteki chosa de-ta kara). In Chuo Kolon, January 2018.

Konishi, E., Yahiro, M., Nakajima, N. \& Ono, M. (2009). The Japanese Value of Harmony and Nursing Ethics. In Nursing Ethics. 16 (5), 625636.

Liddicoat, A. J. (2007). Internationalizing Japan: Nihonjinron and the Intercultural in Japanese Language-in-Education Policy. In Journal of Multicultural Discourses, 2:1, 32-46.

Marshall, B. (1967). Capitalism and Nationalism in Prewar Japan. Stanford University Press.

McLelland. M. (2012). Love, Sex, and Democracy in Japan during the American Occupation. Palgrave Macmillan.

Miller, R. A. (1982). Japan's Modern Myth: The Language and Beyond. NY: Weatherhill.

Nagatani, K. \& Edgington, D. E. (eds.). (1998). Japan and the West: The Perception Gap. Ashtage.

Naito, T. (1992). Tatemae and Honne: A Study of Moral Relativism in Japanese Culture. In Gielen, U., Loeb-Adler, L. \& Milgram, N. (eds.). Psychology in International Perspective. NY: Garland Science.

Nakane, C. (1970). Japanese Society. London: Weidenfeld and Nicholson.

Owada, T. The Lesson from the Failure of Yamaichi Securities 20 years ago. (Hatan 20 nen yamaichi no kyukun). Tokyo: Asahi, 2017/11/24.

Reishauer, E. O. (1977). The Japanese. Tokyo: Charles E. Tuttle Company. 
Rear, D. (2012). The Dilemma of 'Critical Thinking', Conformism, and Non-Conformism in Japanese Education Policy. In Iles, T. \& Matanle, P. (eds.). Researching Twenty-First Century Japan: New Directions and Approaches for the Electronic Age. NY, Toronto, UK: Lexington Books

Smith, H. W. (1995). The Myth of Japanese Homogeneity: Social-Ecological Diversity in Education and Socialization. NY: Nova Science Publishers Inc.

Sugimoto, Y. (1999). Making Sense of Nihonjinron. In Thesis Eleven 57 (1): 81-96.

-. (2010). An Introduction to Japanese Society (3rd edn.). Cambridge University Press.

Sugiyama-Lebra, T. S. (1976). Japanese Patterns of Behaviour. University of Hawaii Press.

-. (2004). The Japanese Self in Cultural Logic. Hawai'i: University of Hawaii Press.

Underwood, J. \& Okubayashi, T. (2013). Comparing the Characteristics of Text-Speak Used by English and Japanese Students. In Zheng, R. (ed.) Evolving Psychological and Educational Perspectives on Cyber Behaviour. USA: Information Science Reference (IGI), 258-271. 
